\title{
Inventory Decisions in a Product-Updated System with Component Substitution and Product Substitution
}

\author{
Yancong Zhou ${ }^{1}$ and Junqing Sun ${ }^{2}$ \\ ${ }^{1}$ School of Information Engineering, Tianjin University of Commerce, Tianjin 300134, China \\ ${ }^{2}$ School of Computer and Communication Engineering, Tianjin University of Technology, Tianjin 300191, China \\ Correspondence should be addressed to Yancong Zhou; zycong78@126.com
}

Received 30 December 2012; Accepted 1 February 2013

Academic Editor: Xiaochen Sun

Copyright (c) 2013 Y. Zhou and J. Sun. This is an open access article distributed under the Creative Commons Attribution License, which permits unrestricted use, distribution, and reproduction in any medium, provided the original work is properly cited.

\begin{abstract}
Substitution behaviors happen frequently when demands are uncertain in a production inventory system, and it has attracted enough attention from firms. Related researches can be clearly classified into firm-driven substitution and customer-driven substitution. However, if production inventory is stock-out when a firm updates its product, the firm may use a new generation product to satisfy the customer's demand of old generation product or use updated component to substitute old component to satisfy production demand. Obviously, two cases of substitution exist simultaneously in the product-updated system when an emergent shortage happens. In this paper, we consider a component order problem with component substitution and product substitution simultaneously in a product-updated system, where the case of firm-driven substitution or customer-driven substitution can be reached by setting different values for two system parameters. Firstly, we formulate the problem into a two-stage dynamic programming. Secondly, we give the optimal decisions about assembled quantities of different types of products. Next, we prove that the expected profit function is jointly concave in order quantities and decrease the feasible domain by determining some bounds for decision variables. Finally, some management insights about component substitution and product substitution are investigated by theoretical analysis method.
\end{abstract}

\section{Introduction}

In an uncertainty environment, substitution is an effective way when planner incurs an emergent shortage, it can maximize the expected profit or minimize risk. For example, when a shortage happens for a supplier, he can choose to fill demands with the inventory of another product to decrease revenue loss; or for a manufacturer, once the shortage happens in manufacturing process, he may use another substitutable component to satisfy production demand. However, the substitution offered by the firm to hedge against uncertainty in future sales or production also increases management difficulty.

According to the current classification, the substitution problem mainly includes firm-driven substitution and customer-driven substitution. The former sources from the assortment problem has been studied adequately. Usually, this substitution happens when a lower grade component is stock-out, and the inventory of another updated component is surplus, which is a one-way substitution (see, e.g., [1], Pasternack and Drezner [2], [3-7]).

While for the latter, the firm only offers a substitution advice, the actual substitution behavior is determined by a large number of independently-minded and self-interested consumers. When the shortage case happens, to retain the original customer or decrease shortage penalty, firm may offer a type of substitutable product to the customers. Whether the customer accepts the substitution advice is affected by the variants in many aspects, such as cost, selling prices, and particular technical attributes.

Customer-driven substitution has also many researches and is more attractive in current issues. The correlated papers can be categorized according to two-product or multiproduct, the centralized or competitive decision, and partial or 
full substitution. Our paper is related to the case with the two product, centralized, and partial substitution (see, e.g., [8-11]).

Current research considered either firm-driven substitution or customer-driven substitution. It is possible that both two cases need to be considered in the same operation environment. For example, a manufacturer produces two products with an updated relation, replenishes the component inventory in advance, and assembles the components into end products according to the customer's order. Because manufacturer makes the replenishment decisions of component inventories before retailer's order arrivals, the shortage for component inventories are inevitable. Therefore, a manufacturer may fill the shortage demand using an updated component so that firm-driven substitution happens. At the mean time, the manufacturer also can stimulate the customer to buy the other product himself by offering a discount price. Certainly, the purchasing decision is made by the customer, so customer-driven substitution happens. However, there is no paper to consider the two cases simultaneously.

Our paper is mostly related to Hale [12]. The paper considers the optimal decision problem in an assemble-toorder system with only component substitution. However, product substitution is also considered in our paper, besides for component substitution. And we study a partial substitution case, and the proportion of substitution is related to a product substitution effort (it may represent an additional production, shipping costs, or loss in revenue, such as giving a price discount for a substitution action). In our problem, there are two important parameters: substitution effort and mark-up value. When substitution effort is zero, the problem can be realized as a pure firm-driven substitution problem. And when mark-up value is very high, the problem can be realized as a pure customer-driven substitution. To the best of our knowledge, our paper is the first paper of integrating product substitution and component substitution.

The rest of this paper is organized as follows. Our model is formulated in Section 2. In Section 3, we provide optimal analysis, present the optimal policy of assembled quantities of different types of products, and give some bounds for ordering decisions. Some management insights are provided in Section 4. Finally, we conclude our paper in Section 5.

\section{Problem Description and Formulation}

A firm facing stochastic market demands produces new generation product and old generation product simultaneously. Each generation product is assembled by two types of components, one type is a specific component and the other is an updateable component. The specific component only can be used to produce a certain type of product alone. However, the updateable component of a new generation product also can be used to produce an old generation product, besides to produce itself. We call the updateable component of a new generation product as substitutable component and call the substitutable component of an old generation product as substituted component. The cost of substitutable component is higher than substituted component. Certainly, it is obvious that an old generation product assembled by its specific component and substitutable component has a higher performance than the products by its specific component and substituted component. We call this type of product as hybrid product, and we assume that its selling price is higher than a pure old generation. The price-increased value of hybrid product is called a mark-up value, denoted by $c_{n o}$. Moreover, a new generation product has a better performance than an old generation product and a hybrid product, so its selling price is the highest. To stimulate a customer into accepting substitution product, the firm will offer a substitution effort, which may represent an additional production costs or shipping costs, or potential loss of customer's goodwill, or loss in revenue (such as giving a price discount for a substitution action), denoted by $C_{n o}$. It means that the customers may not accept product substitution if the firm does not want to offer a satisfying effort level. Therefore, customer's quantity of accepting substitution product is affected by the substitution effort. Let $\theta\left(C_{n o}\right)$ denote substitution proportion of product substitution for given substitution effort. It is obvious that a larger $C_{n o}$ will result in a larger $\theta\left(C_{n o}\right)$. And we assume that $\theta\left(C_{n o}\right)=0$ for $C_{n o}=0$.

The research aim of this paper is to determine the optimal order quantities for all components and the optimal assembled quantities of different types of products in an assembleto-order production system with component substitution and product substitution, so that the expectation of firm's profit is maximized.

The sequence of system events is as follows. Firstly, facing stochastic demands, the firm orders all components. Then, demands are realized. The firm makes decisions on the production quantities of all type of products. If the demands of old generation product cannot be satisfied totally, the firm will consider satisfying the shortage demand by using the surplus new generation product. If demands are still not be satisfied, the firm will consider producing a hybrid product. Finally, the firm assembles current components into end products.

Notation Definitions. For simplifying the following description, we use $i$ and $j$ as the subscript of notation. Let $i=n$ denote new generation product, $i=o$ denote old generation product, $j=1$ denote specific component and $j=2$ denote substitution component. Therefore, we may denote specific component and substitution component by the vector $(i, j)$, for example, $(n, 2)$ denote the substitution component of new generation product, that is, the substitutable component.

$$
\begin{aligned}
& C_{i j}=\text { order cost of per unit component } j \text { of product } \\
& i . \\
& S_{i j}=\text { salvage value of per unit component } j \text { of product } \\
& i . \\
& D_{i}=\text { demand for product } i \text { and is a random variable. } \\
& p_{i}=\text { selling price of product } i \text {. } \\
& c_{n o}=\text { mark-up value of per unit component substitu- } \\
& \text { tion for old generation. } \\
& C_{n o}=\text { substitution effort of per unit product substitu- } \\
& \text { tion. }
\end{aligned}
$$




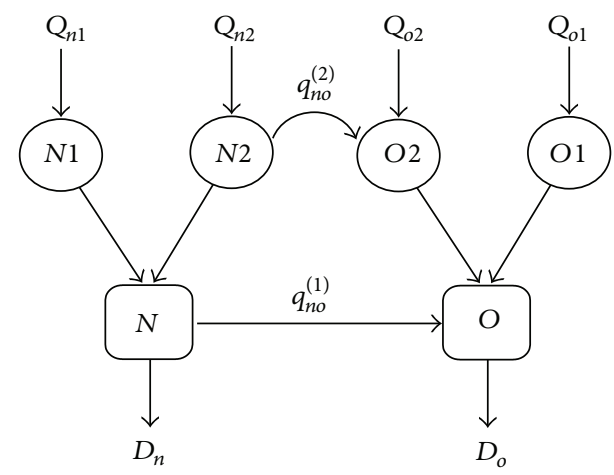

FIGURE 1: Notation sketch figure.

$\theta\left(C_{n o}\right)=$ substitution proportion of product substitution for a given substitution effort.

$Q_{i j}=$ order quantity of component $j$ of product $i$.

$q_{n n}=$ assembled quantity of new generation product composed by its specific component and substitutable component.

$q_{o o}=$ assembled quantity of old generation product composed by its specific component and substituted component.

$q_{n o}^{(1)}=$ product quantity for satisfying product substitution.

$q_{n o}^{(2)}=$ hybrid product quantity for satisfying component substitution.

We can figure a part of notations by Figure 1 .

Firstly, we give some assumptions about system parameters.

Assumption 1. $p_{n}-C_{n 1}-C_{n 2}-C_{n o}>p_{o}+c_{n o}-C_{n 2}-C_{o 2}$. It means that the revenue of the case of product substitution is larger than the case of component substitution.

Assumption 2. $C_{o 2}-S_{o 2}<C_{n 2}-S_{n 2}$. It denotes that the cost loss of per unit surplus substitutable component is larger than per unit surplus substituted component.

Assumption 3. $c_{n o} \leq C_{n 2}-C_{o 2}$. It means that the mark-up value should not be larger than the added cost for component substitution. Generally, the firm should bear some duties for the shortage as firm's reason.

Assumption 4. $p_{n}-C_{n o}-S_{n 1}-S_{n 2}>p_{o}+c_{n o}-S_{o 1}-S_{n 2}>$ 0 . It means that the selling revenue is larger than salvages, otherwise, the firm has no motivation to sell end products. It also means that the firm has a larger motivation to offer product substitution to the customer than to offer component substitution.
Let $Q=\left(Q_{n 1}, Q_{n 2}, Q_{o 1}, Q_{n 2}\right)$ and $q=\left(q_{n n}, q_{o o}, q_{n o}^{(1)}, q_{n o}^{(2)}\right)$, from the sequence of system events, the optimization problem is given as follows:

$$
\max _{Q} \Pi=\max _{Q}\left\{-\sum_{i=n, o} \sum_{j=1,2} C_{i j} Q_{i j}+E\left[\pi\left(Q, D_{n}, D_{o}\right)\right]\right\},
$$

where

$$
\begin{aligned}
& \pi\left(Q, d_{n}, d_{o}\right)=\max _{q}\left\{p_{n} q_{n n}+p_{o} q_{o o}+\left(p_{n}-C_{n o}\right) q_{n o}^{(1)}\right. \\
& +\left(p_{o}+c_{n o}\right) q_{n o}^{(2)} \\
& +S_{n 1}\left(Q_{n 1}-q_{n n}-q_{n o}^{(1)}\right) \\
& +S_{o 1}\left(Q_{o 1}-q_{o o}-q_{n o}^{(2)}\right) \\
& +S_{n 2}\left(Q_{n 2}-q_{n n}-q_{n o}^{(1)}-q_{n o}^{(2)}\right) \\
& \left.+S_{o 2}\left(Q_{o 2}-q_{o o}\right)\right\} \\
& \text { s.t. }\left\{\begin{array}{l}
q_{n n} \leq d_{n} \\
q_{o o}+q_{n o}^{(1)}+q_{n o}^{(2)} \leq d_{o} \\
q_{n n}+q_{n o}^{(1)} \leq Q_{n 1} \\
q_{n n}+q_{n o}^{(1)}+q_{n o}^{(2)} \leq Q_{n 2} \\
q_{o o} \leq Q_{o 2} \\
q_{o o}+q_{n o}^{(2)} \leq Q_{o 1} \\
q_{n n}, q_{o o}, q_{n o}^{(1)}, q_{n o}^{(2)} \geq 0 .
\end{array}\right.
\end{aligned}
$$

Let $Q^{*}=\left(Q_{n 1}^{*}, Q_{n 2}^{*}, Q_{o 1}^{*}, Q_{o 2}^{*}\right)$ denote the optimal solution in (1) and $q^{*}=\left(q_{n n}^{*}, q_{o o}^{*}, q_{n o}^{(1 *)}, q_{n o}^{(2 *)}\right)$ denote the optimal solution of optimization problem in (2). In the following, we will make optimal analyses for the optimal solutions $Q^{*}$ and $q^{*}$.

\section{Optimal Analysis}

The aforementioned optimization problem is a two-stage stochastic dynamic programming. We need to solve $\pi\left(Q, D_{n}, D_{o}\right)$ in (2), firstly, then solve the optimization problem in (1).

3.1. Optimal Assemble Decisions. To find the optimal solution $q^{*}$, we need to firstly give a property about optimal orders of several types of components.

Property 1. The optimal orders of several types of components satisfy
(a) $Q_{n 1}^{*} \leq Q_{n 2}^{*}$,
(b) $Q_{o 2}^{*} \leq Q_{o 1}^{*}$. 
Proof. From the constraints $q_{n n}+q_{n o}^{(1)} \leq Q_{n 1}$ and $q_{n n}+$ $q_{n o}^{(1)}+q_{n o}^{(2)} \leq Q_{n 2}$, we know that if $Q_{n 1}^{*}>Q_{n 2}^{*}$, there must be $q_{n n}^{*}+q_{n o}^{(1 *)}<Q_{n 1}$ for any realized demand, that is, the specific component of new generation product must be surplus, which means $Q_{n 1}^{*}$ is not optimal. Therefore, we have $Q_{n 1}^{*} \leq Q_{n 2}^{*}$. Similar to the process, we also can prove that part (b) holds.

Property 1 means that the optimal order quantity of substitutable component is larger than the optimal order quantity of specific component of new generation product. However, for old generation product, the optimal order quantity of substituted component is less than the optimal order quantity of specific component of new generation product. Because the substitutable component needs to meet an additional demand except for the original demand, and the substituted component has an additional supply source, the property is obvious.

Property 1 not only give the bound constraints about the optimal order quantities of several types of components which is meaningful for shrinking the feasible domain by adding the constraints $Q_{n 1} \leq Q_{n 2}$ and $Q_{o 2} \leq Q_{o 1}$, but also important for analyzing the properties of optimization model. In the following, we will give the optimal decisions of assembled quantities.

Theorem 1. Given the order quantity vector $\left(Q_{n 1}, Q_{n 2}\right.$, $\left.Q_{o 1}, Q_{n 2}\right)$ and the realized demand $\left(d_{n}, d_{o}\right)$, the optimal assembled quantities for all types of products are as follows:

$$
\begin{gathered}
q_{n n}^{*}=\min \left\{d_{n}, Q_{n 1}\right\} \\
q_{o o}^{*}=\min \left\{d_{o}, Q_{o 2}\right\} \\
q_{n o}^{(1 *)}=\min \left\{\max \left\{Q_{n 1}-d_{n}, 0\right\},\right. \\
\left.\max \left\{\theta\left(C_{n o}\right)\left(d_{o}-Q_{o 2}\right), 0\right\}\right\} \\
q_{n o}^{(2 *)}=\min \left\{Q_{n 2}-\min \left\{d_{n}, Q_{n 1}\right\},\right. \\
\left.\max \left\{\min \left\{d_{o}, Q_{o 1}\right\}-Q_{o 2}, 0\right\}\right\} \\
-\min \left\{\max \left\{Q_{n 1}-d_{n}, 0\right\},\right. \\
\left.\theta\left(C_{n o}\right) \max \left\{d_{o}-Q_{o 2}, 0\right\}\right\} .
\end{gathered}
$$

Proof. From Assumption 1, the optimal assemble rule is that firm produces products by the component itself as possible; and if old generation product is shortage, the firm should firstly consider product substitution and secondly consider component substitution. We analyze the optimal assemble decisions for different cases.

Case 1. When $d_{n}>\min \left\{Q_{n 1}, Q_{n 2}\right\}$ and $d_{0} \leq \min \left\{Q_{o 1}, Q_{o 2}\right\}$, there are $d_{n}>Q_{n 1}$ and $d_{0} \leq Q_{o 2}$ (by Property 1 ), that is, the demands of new generation product can not totally be satisfied, and there is no shortage for old generation product. Therefore,

$$
q_{n n}=Q_{n 1}, \quad q_{n o}^{(1)}=0, \quad q_{o o}=d_{o}, \quad q_{n o}^{(2)}=0 .
$$

Case 2. When $d_{n}>\min \left\{Q_{n 1}, Q_{n 2}\right\}$ and $d_{0}>\min \left\{Q_{o 1}, Q_{o 2}\right\}$, there are $d_{n}>Q_{n 1}$ and $d_{0}>Q_{o 2}$ (by Property 1), that is, both demands of new and old generation product can not totally be satisfied by the components themselves. Therefore, there is no product substitution, but may exist the component substitution. The shortage quantity of substituted component is $\min \left\{d_{o}-Q_{o 2}, Q_{o 1}-Q_{o 2}\right\}$, and the supply quantity of substitutable component is $Q_{n 2}-Q_{n 1}$. We have

$$
\begin{gathered}
q_{n n}=Q_{n 1}, \quad q_{n o}^{(1)}=0, \quad q_{o o}=Q_{o 2}, \\
q_{n o}^{(2)}=\min \left\{Q_{n 2}-Q_{n 1}, \min \left\{d_{o}-Q_{o 2}, Q_{o 1}-Q_{o 2}\right\}\right\} .
\end{gathered}
$$

Case 3. When $d_{n} \leq \min \left\{Q_{n 1}, Q_{n 2}\right\}$ and $d_{o} \leq \min \left\{Q_{o 1}, Q_{o 2}\right\}$, there are $d_{n} \leq Q_{n 1}$ and $d_{0} \leq Q_{o 2}$ (by Property 1), that is, both demands of new and old generation product can totally be satisfied by the components themselves. Therefore, we have

$$
q_{n n}=d_{n}, \quad q_{o o}=d_{o}, \quad q_{n o}^{(1)}=0, \quad q_{n o}^{(2)}=0 .
$$

Case 4. When $d_{n} \leq \min \left\{Q_{n 1}, Q_{n 2}\right\}$ and $d_{0}>\min \left\{Q_{o 1}, Q_{o 2}\right\}$, there are $d_{n} \leq Q_{n 1}$ and $d_{0}>Q_{02}$ (by Property 1), that is, the demands of new generation product can totally be satisfied, and the demands of old generation product can not totally be satisfied by the components itself. So, we have $q_{n n}=d_{n}$ and $q_{o o}=Q_{o 2}$. Product substitution needs to be considered firstly. The maximal supply quantity of new generation product is $Q_{n 1}-d_{n}$, and the demand quantity of new generation product is $d_{o}-Q_{o 2}$. We have

$$
q_{n o}^{(1)}=\min \left\{Q_{n 1}-d_{n}, d_{o}-Q_{o 2}\right\} .
$$

Component substitution also may happen. If the demand shortage of old generation product is totally satisfied by product substitution, then $q_{n o}^{(2)}=0$; otherwise, component substitution happens. The maximal supply quantity of substitutable component is $Q_{n 2}-d_{n}-q_{n o}^{(1)}$, and the shortage of substituted component is $\min \left\{d_{o}, Q_{o 1}\right\}-Q_{o 2}-q_{n o}^{(1)}$. Therefore, we have

$$
\begin{aligned}
q_{n o}^{(2)} & =\min \left\{Q_{n 2}-d_{n}-q_{n o}^{(1)}, \min \left\{d_{o}, Q_{o 1}\right\}-Q_{o 2}-q_{n o}^{(1)}\right\} \\
& =\min \left\{Q_{n 2}-d_{n}, \min \left\{d_{o}-Q_{o 2}, Q_{o 1}-Q_{o 2}\right\}\right\}-q_{n o}^{(1)} .
\end{aligned}
$$

In summary, we can denote the optimal assembled quantities by a uniform form, that is, (3). The theorem holds.

3.2. Bounds of Order Decisions. By Theorem 1, we can rewrite $\pi\left(Q, d_{n}, d_{o}\right)$ in (1) as follows: 


$$
\begin{aligned}
\pi\left(Q, d_{n}, d_{o}\right)= & \left(p_{n}-S_{n 1}-S_{n 2}\right) \min \left\{d_{n}, Q_{n 1}\right\} \\
& +\left(p_{o}-S_{o 1}-S_{o 2}\right) \min \left\{d_{o}, Q_{o 2}\right\} \\
& +\sum_{j=i, 2} \sum_{i=n, o} S_{i j} Q_{i j} \\
& +\left(p_{n}-C_{n o}-S_{n 1}-\left(p_{o}+c_{n o}-S_{o 1}\right)\right) \\
& \times \min \left\{\max \left\{Q_{n 1}-d_{n}, 0\right\},\right. \\
& +\left(p_{o}+c_{n o}-S_{o 1}-S_{n 2}\right) \\
& \times \min \left\{Q_{n 2}-\min \left\{d_{n}, Q_{n 1}\right\},\right. \\
& \left.\left.\max \left\{\min \left\{d_{o}, Q_{o 1}\right\}-Q_{o 2}\right), 0\right\}\right\}
\end{aligned}
$$

By (1), define

$$
\Pi(Q)=E\left[\pi\left(Q, D_{n}, D_{o}\right)\right]-\sum_{i=n, o} \sum_{j=1,2} C_{i j} Q_{i j} .
$$

We have the following property.

Property 2. $\Pi(Q)$ is jointly concave in the order quantity vector $\left(Q_{n 1}, Q_{n 2}, Q_{o 1}, Q_{n 2}\right)$.

Proof. From the theory of linear programming, the value of a linear maximization programming is concave in the right hand sides of the constraints ([13], page 438-439). Therefore, for the given realized demands $d_{n}$ and $d_{o}$, $\pi\left(Q, d_{n}, d_{o}\right)$ is jointly concave in the order quantity vector $\left(Q_{n 1}, Q_{n 2}, Q_{o 1}, Q_{n 2}\right)$. Moreover, $E\left[\pi\left(Q, D_{n}, D_{o}\right)\right]$ is also jointly concave in the order quantity vector $\left(Q_{n 1}, Q_{n 2}, Q_{o 1}, Q_{n 2}\right)$. From (10), it is obvious that $\Pi(Q)$ is concave.

Property 2 shows that the optimal solution is unique. The following property will simplify our analysis.

Property 3. The optimal order quantity of substitutable component is equal to the optimal order quantity of substituted component, that is, $Q_{n 2}^{*}=Q_{n 1}^{*}$.

Proof. From Property 1, we know that the optimal solutions should satisfy $Q_{n 2} \geq Q_{n 1}$ and $Q_{o 2} \leq Q_{o 1}$. We only need to prove that the optimal solutions do not satisfy $Q_{n 2}>Q_{n 1}$ and $Q_{o 2} \leq Q_{o 1}$. We will prove that the system profit of decreasing per unit substitutable component and increasing per unit substituted component will be improved. Let

$$
H(\Delta)=\Pi\left(Q_{n 1}, Q_{n 2}-\Delta, Q_{o 1}, Q_{o 2}+\Delta\right),
$$

where $Q_{n 1} \leq Q_{n 2}-\Delta$ and $Q_{o 1} \geq Q_{o 2}+\Delta$.

The first order condition is as follows:

$$
\begin{aligned}
\frac{d H(\Delta)}{d \Delta}= & \left(p_{o}-S_{o 1}-S_{o 2}\right) \operatorname{Pr}\left\{D_{o}>Q_{o 2}+\Delta\right\}-\left(S_{n 2}-C_{n 2}\right) \\
& +S_{o 2}-C_{o 2}+\left(p_{n}-C_{n o}-S_{n 1}-\left(p_{o}+c_{n o}-S_{o 1}\right)\right) \\
& \times \operatorname{Pr}\left\{D_{o}>Q_{o 2}+\Delta, Q_{n 1}>D_{n}, Q_{n 1}\right.
\end{aligned}
$$

$$
\begin{aligned}
& \left.-D_{n}>\theta\left(C_{n o}\right)\left(D_{o}-Q_{o 2}-\Delta\right)\right\} \\
& -\left(p_{o}+c_{n o}-S_{o 1}-S_{n 2}\right) \operatorname{Pr}\left\{D_{o}>Q_{o 2}+\Delta\right\} \\
> & \left(S_{n 2}-S_{o 2}-c_{n o}\right) \operatorname{Pr}\left\{D_{o}>Q_{o 2}+\Delta\right\} \\
& -\left(S_{n 2}-C_{n 2}\right)+S_{o 2}-C_{o 2} \\
\geq & \left(S_{n 2}-S_{o 2}-\left(C_{n 2}-C_{o 2}\right)\right) \operatorname{Pr}\left\{D_{o}>Q_{o 2}+\Delta\right\} \\
& -\left(S_{n 2}-C_{n 2}\right)+S_{o 2}-C_{o 2} \\
= & \left(C_{o 2}-S_{o 2}-\left(C_{n 2}-S_{n 2}\right)\right) \\
& \times\left(\operatorname{Pr}\left\{D_{o}>Q_{o 2}+\Delta\right\}-1\right) \\
> & 0 .
\end{aligned}
$$

For the aforementioned process, the first inequality in (12) is because of (13), and the second inequality is because of Assumption 3,

$$
\begin{aligned}
p_{n}- & C_{n o}-S_{n 1}-\left(p_{o}+c_{n o}-S_{o 1}\right) \\
= & p_{n}-C_{n o}-S_{n 1}-S_{n 2} \\
& \quad-\left(p_{o}+c_{n o}-S_{o 1}-S_{n 2}\right)>0 .
\end{aligned}
$$

The theorem holds.

Therefore, we have $H\left(Q_{n 2}-Q_{n 1}\right)=\Pi\left(Q_{n 1}, Q_{n 1}, Q_{o 1}, Q_{o 2}+\right.$ $\left.Q_{n 2}-Q_{n 1}\right)>\Pi\left(Q_{n 1}, Q_{n 2}, Q_{o 1}, Q_{o 2}\right)$, that is, the optimal solution of $\max \left\{\Pi\left(Q_{n 1}, Q_{n 2}, Q_{o 1}, Q_{o 2}\right)\right\}$ must satisfy the constraint $Q_{n 2}=Q_{n 1}$.

By Property 3, we can rewrite $\Pi(Q)$ as follows:

$$
\begin{aligned}
& \Pi(Q)= \phi_{n} E\left[\min \left\{D_{n}, Q_{n 1}\right\}\right]+\phi_{o} E\left[\min \left\{D_{o}, Q_{o 2}\right\}\right] \\
&+\sum_{j=i, 2} \sum_{i=n, o}\left(S_{i j}-C_{i j}\right) Q_{i j} \\
&+ \phi_{n o}^{(1)} E\left[\operatorname { m i n } \left\{\max \left\{Q_{n 1}-D_{n}, 0\right\},\right.\right. \\
&\left.\left.\max \left\{\theta\left(C_{n o}\right)\left(D_{o}-Q_{o 2}\right), 0\right\}\right\}\right] \\
&+\phi_{n o}^{(2)} E\left[\operatorname { m i n } \left\{Q_{n 1}-\min \left\{D_{n}, Q_{n 1}\right\},\right.\right. \\
&\left.\left.\max \left\{\min \left\{D_{o}, Q_{o 1}\right\}-Q_{o 2}, 0\right\}\right\}\right],
\end{aligned}
$$

where

$$
\begin{gathered}
\phi_{n}=p_{n}-S_{n 1}-S_{n 2}, \quad \phi_{o}=p_{o}-S_{o 1}-S_{o 2} \\
\phi_{n o}^{(1)}=p_{n}-C_{n o}-S_{n 1}-\left(p_{o}+c_{n o}-S_{o 1}\right) \\
\phi_{n o}^{(2)}=p_{o}+c_{n o}-S_{o 1}-S_{n 2} .
\end{gathered}
$$

And, moreover, the original optimization problem in (1) is translated into an optimization problem with three decision variables. And $\Pi(Q)$ is concave in $Q$. 
The first order conditions are as follows:

$$
\begin{aligned}
\frac{\partial \Pi(Q)}{\partial Q_{n 1}}= & \phi_{n} \operatorname{Pr}\left\{D_{n}>Q_{n 1}\right\} \\
& +\phi_{n o}^{(1)} \operatorname{Pr}\left\{Q_{n 1}>D_{n}, D_{o}>Q_{o 2}\right. \\
& \left.\quad Q_{n 1}-D_{n}<\theta\left(C_{n o}\right)\left(D_{o}-Q_{o 2}\right)\right\} \\
+ & S_{n 1}-C_{n 1}+S_{n 2}-C_{n 2} \\
+ & \phi_{n o}^{(2)} \operatorname{Pr}\left\{D_{o}>Q_{o 2}, D_{n}<Q_{n 1},\right. \\
& \left.\quad Q_{n 1}-D_{n}<\min \left\{D_{o}, Q_{o 1}\right\}-Q_{o 2}\right\}
\end{aligned}
$$

$$
\begin{aligned}
\frac{\partial \Pi(Q)}{\partial Q_{o 1}}= & S_{o 1}-C_{o 1} \\
& \\
& +\phi_{n o}^{(2)} \operatorname{Pr}\left\{D_{o}>Q_{o 1}, D_{n} \leq Q_{n 1},\right. \\
& \left.\quad Q_{n 1}-D_{n}>Q_{o 1}-Q_{o 2}\right\},
\end{aligned}
$$$$
\frac{\partial \Pi(Q)}{\partial Q_{o 2}}=\phi_{o} \operatorname{Pr}\left\{D_{o}>Q_{o 2}\right\}
$$$$
-\phi_{n o}^{(2)} \operatorname{Pr}\left\{D_{o}>Q_{o 2}, D_{n} \leq Q_{n 1},\right.
$$$$
\left.Q_{n 1}-D_{n}>\min \left\{D_{o}, Q_{o 1}\right\}-Q_{o 2}\right\}
$$$$
+S_{o 2}-C_{o 2}-\theta\left(C_{n o}\right)
$$$$
\times \phi_{n o}^{(1)} \operatorname{Pr}\left\{Q_{n 1}>D_{n}, D_{o}>Q_{o 2},\right.
$$$$
\left.Q_{n 1}-D_{n}>\theta\left(C_{n o}\right)\left(D_{o}-Q_{o 2}\right)\right\} \text {. }
$$

Obviously, it is difficult to gain the analytical solutions by the first order conditions. Therefore, we will decrease the feasible domain by giving some bounds about decision variables.

Theorem 2. A lower bound of $Q_{n 1}^{*}$ is the solution of $\operatorname{Pr}\left\{D_{n} \leq\right.$ $\left.Q_{n 1}\right\}=\left(p_{n}-C_{n 1}-C_{n 2}\right) /\left(p_{n}-S_{n 1}-S_{n 2}\right)$.

Proof. From (13), $\phi_{\text {no }}^{(1)}>0$, and from Assumption $4, \phi_{n o}^{(2)}>0$, we have

$$
\begin{aligned}
\frac{\partial \Pi(Q)}{\partial Q_{n 1}} \geq & \phi_{n} \operatorname{Pr}\left\{D_{n}>Q_{n 1}\right\} \\
& +S_{n 1}-C_{n 1}+S_{n 2}-C_{n 2} \\
= & -\left(p_{n}-S_{n 1}-S_{n 2}\right) \operatorname{Pr}\left\{D_{n} \leq Q_{n 1}\right\} \\
& +p_{n}-C_{n 1}-C_{n 2} .
\end{aligned}
$$

From Property 2, the solution of $\operatorname{Pr}\left\{D_{n} \leq Q_{n 1}\right\}=\left(p_{n}-C_{n 1}-\right.$ $\left.C_{n 2}\right) /\left(p_{n}-S_{n 1}-S_{n 2}\right)$ is a lower bound of $Q_{n 1}^{*}$.

From Theorem 2, the optimal order quantity of specific component of new generation product has a lower solution of equaling to a news-vendor solution. And it is not affected by product substitution or component substitution.
Theorem 3. An upper bound of $Q_{n 1}^{*}$ is the solution of

$$
\operatorname{Pr}\left\{Q_{n 1}>D_{n}+D_{o}\right\}=\frac{p_{n}-C_{n 1}-C_{n 2}}{p_{n}+C_{n o}-S_{n 1}-S_{n 2}} .
$$

Proof. From (14),

$$
\begin{aligned}
\frac{\partial \Pi(Q)}{\partial Q_{n 1}} \leq & \phi_{n} \operatorname{Pr}\left\{D_{n}>Q_{n 1}\right\}+\phi_{n o}^{(1)} \\
& \times \operatorname{Pr}\left\{Q_{n 1}>D_{n}, Q_{n 1}-D_{n}<D_{o}\right\} \\
& +S_{n 1}-C_{n 1}+S_{n 2}-C_{n 2} \\
& +\phi_{n o}^{(2)} \operatorname{Pr}\left\{D_{n}<Q_{n 1}, Q_{n 1}-D_{n}<D_{o}\right\} \\
= & -\left(p_{n}-S_{n 1}-S_{n 2}\right) \operatorname{Pr}\left\{D_{n}<Q_{n 1}, Q_{n 1} \geq D_{n}+D_{o}\right\} \\
& +\left(p_{n}-C_{n 1}-C_{n 2}\right) \\
& -C_{n o} \operatorname{Pr}\left\{D_{n}<Q_{n 1}, Q_{n 1}<D_{n}+D_{o}\right\} \\
\leq & -\left(p_{n}+C_{n o}-S_{n 1}-S_{n 2}\right) \operatorname{Pr}\left\{Q_{n 1}>D_{n}+D_{o}\right\} \\
& +p_{n}-C_{n 1}-C_{n 2} .
\end{aligned}
$$

Therefore, from Property 2, the solution of $\operatorname{Pr}\left\{Q_{n 1}>D_{n}+\right.$ $\left.D_{o}\right\}=\left(p_{n}-C_{n 1}-C_{n 2}\right) /\left(p_{n}+C_{n o}-S_{n 1}-S_{n 2}\right)$ is an upper bound of $Q_{n 1}^{*}$.

Theorem 4. An upper bound of $Q_{o 1}^{*}$ is the solution of $\operatorname{Pr}\left\{D_{o} \leq Q_{o 1}\right\}=\left(p_{o}+c_{n o}-C_{o 1}-S_{n 2}\right) /\left(p_{o}+c_{n o}-S_{o 1}-S_{n 2}\right)$.

Proof. From (17), we have

$$
\begin{aligned}
\frac{\partial \Pi(Q)}{\partial Q_{o 1}}= & S_{o 1}-C_{o 1}+\left(p_{o}+c_{n o}-S_{o 1}-S_{n 2}\right) \\
& \times \operatorname{Pr}\left\{D_{o}>Q_{o 1}, Q_{n 1}+Q_{o 2}-Q_{o 1}>D_{n}\right\} \\
\leq & \left(p_{o}+c_{n o}-C_{o 1}-S_{n 2}\right) \\
& -\left(p_{o}+c_{n o}-S_{o 1}-S_{n 2}\right) \operatorname{Pr}\left\{D_{o} \leq Q_{o 1}\right\} .
\end{aligned}
$$

Therefore, from Property 2, the solution of $\operatorname{Pr}\left\{D_{o} \leq\right.$ $\left.Q_{o 1}\right\}=\left(p_{o}+c_{n o}-C_{o 1}-S_{n 2}\right) /\left(p_{o}+c_{n o}-S_{o 1}-S_{n 2}\right)$ is an upper bound of $Q_{o 1}^{*}$.

Theorem 5. An upper bound of $Q_{o 2}^{*}$ is the solution of $\operatorname{Pr}\left\{D_{o}<Q_{o 2}\right\}=\left(p_{o}-C_{o 2}-C_{o 1}\right) /\left(p_{o}-S_{o 1}-S_{o 2}\right)$.

Proof. From $\partial \Pi(Q) / \partial Q_{o 1}=0$, we have

$$
\begin{gathered}
\operatorname{Pr}\left\{D_{o}>Q_{o 1}, D_{n}<Q_{n 1}, Q_{n 1}-D_{n}>Q_{o 1}-Q_{o 2}\right\} \\
=\frac{C_{o 1}-S_{o 1}}{p_{o}+c_{n o}-S_{o 1}-S_{n 2}} .
\end{gathered}
$$


Moreover, substituting the above equation into (18), we have

$$
\begin{aligned}
\frac{\partial \Pi(Q)}{\partial Q_{o 2}}= & \phi_{o} \operatorname{Pr}\left\{D_{o}>Q_{o 2}\right\} \\
& -\phi_{n o}^{(2)} \operatorname{Pr}\left\{D_{o}>Q_{o 1}, D_{n} \leq Q_{n 1},\right. \\
& \left.Q_{n 1}-D_{n}>Q_{o 1}-Q_{o 2}\right\} \\
& -\phi_{n o}^{(2)} \operatorname{Pr}\left\{D_{o}>Q_{o 2},\right. \\
D_{o} \leq Q_{o 1}, D_{n} \leq Q_{n 1}, & \left.Q_{n 1}-D_{n}>D_{o}-Q_{o 2}\right\} \\
& +S_{o 2}-C_{o 2}-\theta\left(C_{n o}\right) \phi_{n o}^{(1)} \\
& \times \operatorname{Pr}\left\{Q_{n 1}>D_{n}, D_{o}>Q_{o 2},\right. \\
& \left.Q_{n 1}-D_{n}>\theta\left(C_{n o}\right)\left(D_{o}-Q_{o 2}\right)\right\} \\
\leq & -\left(p_{o}-S_{o 1}-S_{o 2}\right) \operatorname{Pr}\left\{D_{o} \leq Q_{o 2}\right\} \\
& +p_{o}-C_{o 2}-C_{o 1} \cdot
\end{aligned}
$$

Therefore, the solution of $\operatorname{Pr}\left\{D_{o}<Q_{o 2}\right\}=\left(p_{o}-C_{o 2}-\right.$ $\left.C_{o 1}\right) /\left(p_{o}-S_{o 1}-S_{o 2}\right)$ is an upper bound of $Q_{o 2}^{*}$.

From Theorem 5, the optimal order quantity of substituted component has an upper bound of equaling to a newsvendor solution. And it is not affected by product substitution or component substitution.

The aforementioned theorems about bounds of optimal decisions have two actions. One is to decrease the feasible domain of decision variables, which is very helpful for finding the optimal decisions. The other action is to assist us to make the sensitivity analysis.

\section{Management Insights}

In this section, we will investigate management insights about product substitution and component substitution by the first order conditions and the bounds in Theorems 25. For the single-period problem, we can give the following propositions by theoretical analysis rather than numerical analysis.

Proposition 6. The optimal order quantity of any type of component for new generation product is larger for the case of considering product substitution and component product simultaneously than the case of only considering component substitution.

Proof. When $C_{n o}=0, \theta\left(C_{n o}\right)=0$, which means that no customer accept product substitution, that is, there is no product substitution. From (16), we have

$$
\begin{aligned}
& \left.\frac{\partial \Pi(Q)}{\partial Q_{n 1}}\right|_{C_{n o}>0, c_{n o}>0} \\
& \quad=\phi_{n} \operatorname{Pr}\left\{D_{n}>Q_{n 1}\right\} \\
& \quad+\phi_{n o}^{(1)} \operatorname{Pr}\left\{Q_{n 1}>D_{n}, D_{o}>Q_{o 2},\right.
\end{aligned}
$$

$$
\begin{gathered}
\left.Q_{n 1}-D_{n}<\theta\left(C_{n o}\right)\left(D_{o}-Q_{o 2}\right)\right\} \\
+S_{n 1}-C_{n 1}+S_{n 2}-C_{n 2} \\
+\phi_{n o}^{(2)} \operatorname{Pr}\left\{D_{o}>Q_{o 2}, D_{n}<Q_{n 1},\right. \\
\left.Q_{n 1}-D_{n}<\min \left\{D_{o}, Q_{o 1}\right\}-Q_{o 2}\right\} \\
>\phi_{n} \operatorname{Pr}\left\{D_{n}>Q_{n 1}\right\}+S_{n 1}-C_{n 1}+S_{n 2}-C_{n 2} \\
+\phi_{n o}^{(2)} \operatorname{Pr}\left\{D_{o}>Q_{o 2}, D_{n}<Q_{n 1},\right. \\
\left.Q_{n 1}-D_{n}<\min \left\{D_{o}, Q_{o 1}\right\}-Q_{o 2}\right\} \\
=\left.\frac{\partial \prod(Q)}{\partial Q_{n 1}}\right|_{C_{n o}=0, c_{n o}>0},
\end{gathered}
$$

so $Q_{n 1}^{*}\left(C_{n o}\right)>Q_{n 1}^{*}(0)$. The proposition holds.

Proposition 7. The optimal order quantity of any type of component of new generation product is nonincreasing in substitution effort.

Proof. The solution of $\operatorname{Pr}\left\{Q_{n 1}>D_{n}+D_{o}\right\}=\left(p_{n}-C_{n 1}-\right.$ $\left.C_{n 2}\right) /\left(p_{n}+C_{n o}-S_{n 1}-S_{n 2}\right)$ is decreasing in substitution effort $C_{n o}$. So, the feasible domain of $Q_{n 1}$ is decreasing in $C_{n o}$. The proposition holds.

Proposition 8. The optimal order quantity of specific component of new generation product is larger for the case of considering mark-up value and substitution effort simultaneously than the case without mark-up value and substitution effort. And, for the case of considering product substitution, the optimal order quantity of specific component of new generation product is larger for the case of not considering mark-up value.

Proof. From (16), we have

$$
\begin{aligned}
& \left.\frac{\partial \Pi(Q)}{\partial Q_{n 1}}\right|_{C_{n o}>0, c_{n o}>0} \\
& =\phi_{n} \operatorname{Pr}\left\{D_{n}>Q_{n 1}\right\} \\
& +\phi_{n o}^{(2)} \operatorname{Pr}\left\{D_{o}>Q_{o 2}, D_{n}<Q_{n 1},\right. \\
& \left.\quad Q_{n 1}-D_{n}<\min \left\{D_{o}, Q_{o 1}\right\}-Q_{o 2}\right\} \\
& +S_{n 1}-C_{n 1}+S_{n 2}-C_{n 2} \\
& +\phi_{n o}^{(1)} \operatorname{Pr}\left\{Q_{n 1}>D_{n}, D_{o}>Q_{o 2},\right. \\
& \left.\quad Q_{n 1}-D_{n}<\theta\left(C_{n o}\right)\left(D_{o}-Q_{o 2}\right)\right\} \\
& > \\
& +\phi_{n} \operatorname{Pr}\left\{D_{n}>Q_{n 1}\right\}+S_{n 1}-C_{n 1} \\
& +S_{n 2}-C_{n 2}+\left(p_{o}-S_{o 1}-S_{n 2}\right) \\
& \quad \times \operatorname{Pr}\left\{D_{o}>Q_{o 2}, D_{n}<Q_{n 1}, Q_{n 1}\right.
\end{aligned}
$$




$$
\begin{aligned}
& \left.-D_{n}<\min \left\{D_{o}, Q_{o 1}\right\}-Q_{o 2}\right\} \\
& =\left.\frac{\partial \Pi(Q)}{\partial Q_{n 1}}\right|_{C_{n o}=0, c_{n o}=0} .
\end{aligned}
$$

Therefore, the front half part in this proposition holds. From the following inequality:

$$
\begin{aligned}
& \left.\frac{\partial \Pi(Q)}{\partial Q_{n 1}}\right|_{C_{n o}=0, c_{n o}>0} \\
& =\phi_{n} \operatorname{Pr}\left\{D_{n}>Q_{n 1}\right\}+S_{n 1}-C_{n 1}+S_{n 2}-C_{n 2} \\
& +\phi_{n o}^{(2)} \operatorname{Pr}\left\{D_{o}>Q_{o 2}, D_{n}<Q_{n 1},\right. \\
& \left.\quad Q_{n 1}-D_{n}<\min \left\{D_{o}, Q_{o 1}\right\}-Q_{o 2}\right\} \\
& >\phi_{n} \operatorname{Pr}\left\{D_{n}>Q_{n 1}\right\}+S_{n 1}-C_{n 1}+S_{n 2}-C_{n 2} \\
& +\left(p_{o}-S_{o 1}-S_{n 2}\right) \\
& \quad \times \operatorname{Pr}\left\{D_{o}>Q_{o 2}, D_{n}<Q_{n 1},\right. \\
& \left.\quad Q_{n 1}-D_{n}<\min \left\{D_{o}, Q_{o 1}\right\}-Q_{o 2}\right\} \\
& =\left.\frac{\partial \Pi(Q)}{\partial Q_{n 1}}\right|_{C_{n o}=0, c_{n o}=0} .
\end{aligned}
$$
holds.

So, the second part also holds. Therefore, the proposition

Proposition 9. The optimal order quantity of specific component of old generation product is larger for the case of considering mark-up value of component substitution than the case of not considering it.

Proof. From (17), we have

$$
\begin{aligned}
& \left.\frac{\partial \Pi(Q)}{\partial Q_{o 1}}\right|_{c_{n o}>0}=S_{o 1}-C_{o 1}+\left(p_{o}+c_{n o}-S_{o 1}-S_{n 2}\right) \\
& \quad \times \operatorname{Pr}\left\{D_{o}>Q_{o 1}, D_{n} \leq Q_{n 1}, Q_{n 1}-D_{n}>Q_{o 1}-Q_{o 2}\right\} \\
& \geq S_{o 1}-C_{o 1} \\
& \quad+\left(p_{o}-S_{o 1}-S_{n 2}\right) \\
& \quad \times \operatorname{Pr}\left\{D_{o}>Q_{o 1}, D_{n} \leq Q_{n 1}, Q_{n 1}-D_{n}>Q_{o 1}-Q_{o 2}\right\} \\
& =\left.\frac{\partial \Pi(Q)}{\partial Q_{o 1}}\right|_{c_{n o}=0},
\end{aligned}
$$

so $Q_{o 1}^{*}\left(c_{n o}\right)>Q_{o 1}^{*}(0)$. The proposition holds.

Proposition 10. The optimal order quantity of specific component of old generation product is nondecreasing in mark-up value.

Proof. The solution of $\operatorname{Pr}\left\{D_{o} \leq Q_{o 1}\right\}=\left(p_{o}+c_{n o}-C_{o 1}-\right.$ $\left.S_{n 2}\right) /\left(p_{o}+c_{n o}-S_{o 1}-S_{n 2}\right)$ is increasing in mark-up value $c_{n o}$. Therefore, the proposition is obvious.
Proposition 11. The optimal order quantity of substituted component of old generation product is less for the case of considering product substitution and component substitution simultaneously than the case of only considering component substitution.

Proof. From (18), we have

$$
\begin{aligned}
& \left.\frac{\partial \Pi(Q)}{\partial Q_{o 2}}\right|_{C_{n o}>0, c_{n o}>0} \\
& =\phi_{o} \operatorname{Pr}\left\{D_{o}>Q_{o 2}\right\}+S_{o 1}-C_{o 1}+S_{o 2}-C_{o 2} \\
& \quad-\phi_{n o}^{(2)} \operatorname{Pr}\left\{D_{o}>Q_{o 2}, D_{o} \leq Q_{o 1}, D_{n} \leq Q_{n 1},\right. \\
& \left.\quad Q_{n 1}-D_{n}>D_{o}-Q_{o 2}\right\} \\
& -\theta\left(C_{n o}\right) \phi_{n o}^{(1)} \operatorname{Pr}\left\{Q_{n 1}>D_{n}, D_{o}>Q_{o 2},\right. \\
& \left.\quad Q_{n 1}-D_{n}>\theta\left(C_{n o}\right)\left(D_{o}-Q_{o 2}\right)\right\} \\
& <\phi_{o} \operatorname{Pr}\left\{D_{o}>Q_{o 2}\right\}+S_{o 1}-C_{o 1}+S_{o 2}-C_{o 2} \\
& -\phi_{n o}^{(2)} \operatorname{Pr}\left\{D_{o}>Q_{o 2}, D_{o} \leq Q_{o 1},\right. \\
& \left.\quad D_{n} \leq Q_{n 1}, Q_{n 1}-D_{n}>D_{o}-Q_{o 2}\right\} \\
& =\left.\frac{\partial \Pi(Q)}{\partial Q_{o 2}}\right|_{C_{n o}=0, c_{n o}>0},
\end{aligned}
$$

so $Q_{o 2}^{*}\left(C_{n o}\right)<Q_{o 2}^{*}(0)$. The proposition holds.

From the aforementioned proposition above, if the firm wants to decrease shortage by substitution, it must order more components than the case of no substitution behaviors. Moreover, when product substitution is also introduced, the order quantities for all types of component of new generation should be increased; but for old generation product, the order quantity of its substituted component should be decreased, and the order quantity of specific component should be increased.

The existence of mark-up value is a positive stimulation, to more effective cope with the emergent shortage, firm should store more specific components of old generation product, and it is also same for all type components of new generation product. For product substitution, the existence of substitution effort attracts partial customers of old generation product to buy new generation product, so the firm should order more components of new generation product in order to satisfy the demand of product substitution. However, increasing of the cost will decrease firm's activity of offering product substitution, so the order quantity should not be increasing as substitution effort increases.

From a more widely viewpoint of supply chain, introducing mark-up value and substitution effort are helpful for decreasing the shortage, and it is also an effective way of increasing the service level. 


\section{Conclusion}

In this paper, we study an inventory decision problem with component substitution and product substitution, where a manufacturer produces two products with an updated relation, replenishes the component inventory in advance, and assembles the components into end products according to the customer's order. Since manufacturer makes the replenishment decisions of component inventories before the order arrivals, the shortage for component inventories is inevitable. Therefore, manufacturer may fill the shortage demand using an updated component. At the meanwhile, the manufacturer also can stimulate the customer to buy the other product himself by offering a discount price. We assume a proportion of shortage will purchase new products. To maximize firm's profit, a two-stage dynamic programming model was formulated. And decisions about assembled quantities of different types of products were given. By analyzing the expected profit function, we prove it to be concave in order quantities, and some bounds of decision variables are given. Finally, we investigate the management insights by theoretical method.

There are some possible extensions in the future research. Mark-up value and substitution effort are only regarded as system parameters, in fact, the firm also makes a decision on them. Therefore, the problem will be a joint inventory and a pricing problem, which is very interesting. Certainly, the extension also may result in a game problem between manufacturer and customers.

\section{Acknowledgment}

This research is supported by the National Natural Science Foundation of China (NSFC), research Fund no. 71002106.

\section{References}

[1] A. R. McGillivray and E. A. Silver, "Some concepts for inventory control under substitutable demand," INFOR, vol. 16, no. 1, pp. 47-63, 1978.

[2] B. Pasternack and Z. Drezner, "Optimal inventory policies for substitutable commodities with stochastic demand," Naval Research Logistics, vol. 38, no. 2, pp. 221-240, 1991.

[3] Y. Bassok, R. Anupindi, and R. Akella, "Single-period multiproduct inventory models with substitution," Operations Research, vol. 47, no. 4, pp. 632-642, 1999.

[4] A. Hsu and Y. Bassok, "Random yield and random demand in a production system with downward substitution," Operations Research, vol. 47, no. 2, pp. 277-290, 1999.

[5] H. Gurnani and Z. Drezner, "Deterministic hierarchical substitution inventory models," Journal of the Operational Research Society, vol. 51, no. 1, pp. 129-133, 2000.

[6] V. N. Hsu, C. Li, and W. Xiao, "Dynamic lot size problems with one-way product substitution," IIE Transactions, vol. 37, no. 3, pp. 201-215, 2005.

[7] P. Dutta and D. Chakraborty, "Incorporating one-way substitution policy into the newsboy problem with imprecise customer demand," European Journal of Operational Research, vol. 200, no. 1, pp. 99-110, 2010.
[8] S. Mahajan and G. van Ryzin, "Inventory competition under dynamic consumer choice," Operations Research, vol. 49, no. 5, pp. 646-657, 2001.

[9] K. Rajaram and C. S. Tang, "The impact of product substitution on retail merchandising," European Journal of Operational Research, vol. 135, no. 3, pp. 582-601, 2001.

[10] S. Netessine and N. Rudi, "Centralized and competitive inventory models with demand substitution," Operations Research, vol. 51, no. 2, pp. 329-335, 2003.

[11] M. Nagarajan and S. Rajagopalan, "Inventory models for substitutable products: Optimal policies and heuristics," Management Science, vol. 54, no. 8, pp. 1453-1466, 2008.

[12] W. W. Hale, Assemble-to-order system with component substitution [Ph.D. dissertation], University of Minnesota, Minneapolis, Minn, USA, 2003.

[13] F. Hillier and J. Lieberman, Introduction to Operations Research, Holden-Day, Oakland, Calif, USA, 4th edition, 1986. 


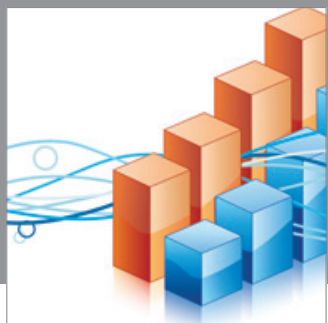

Advances in

Operations Research

mansans

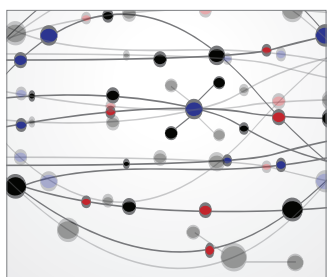

The Scientific World Journal
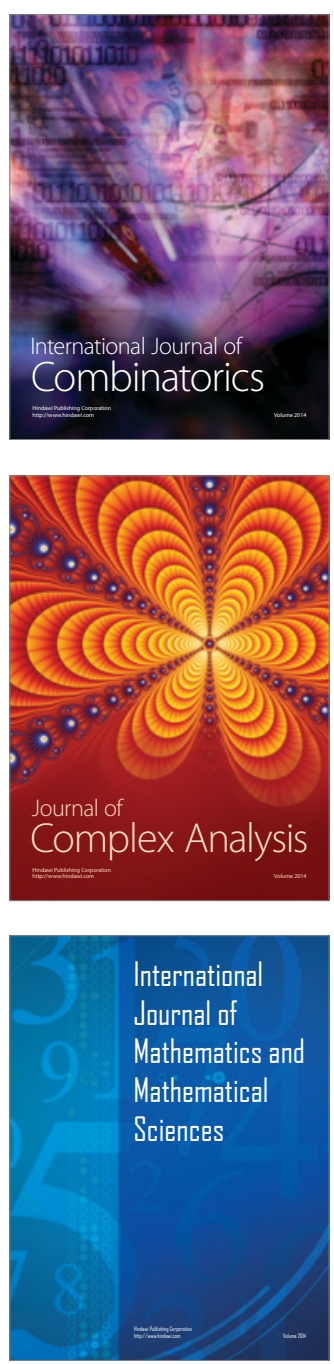
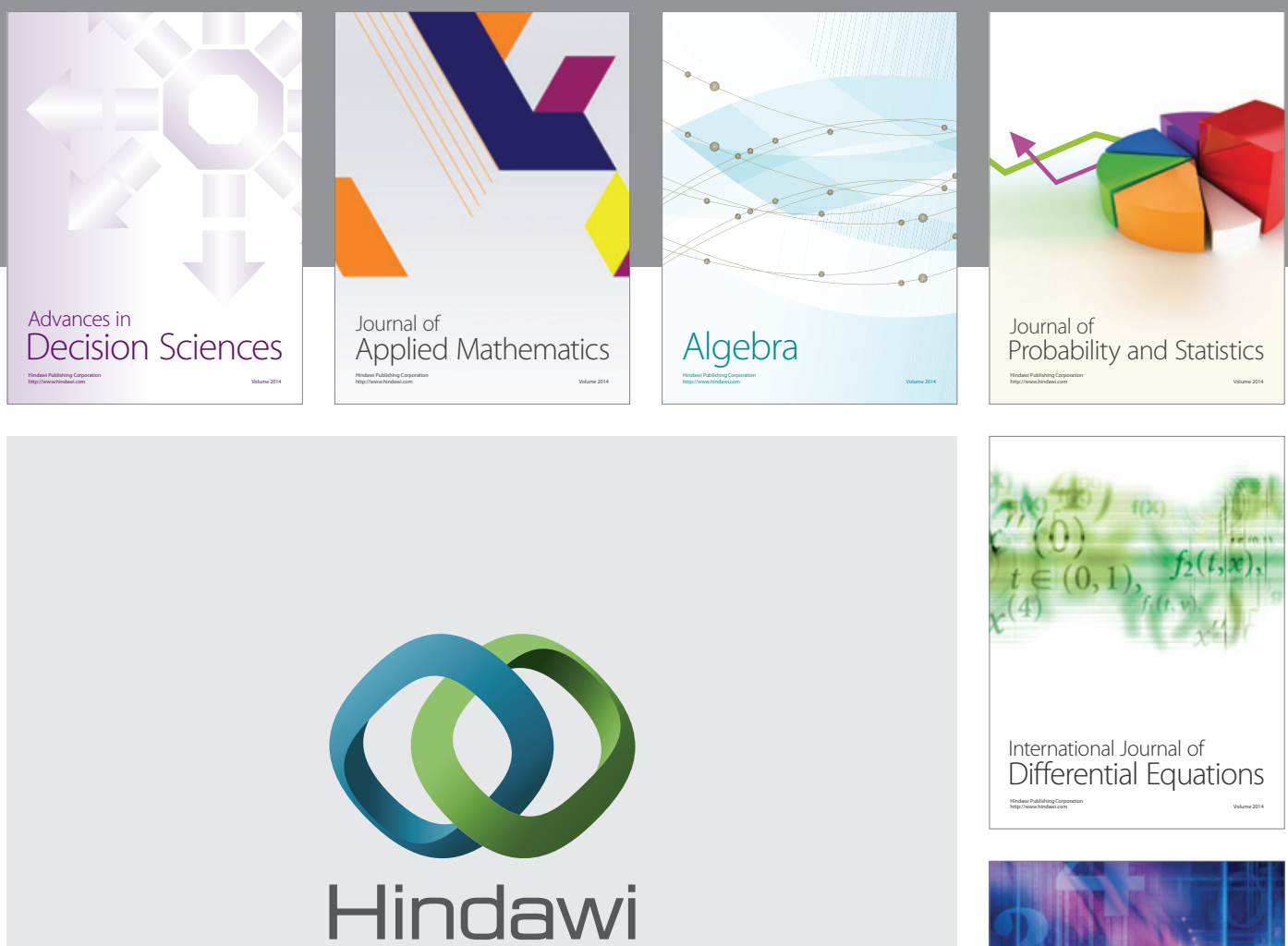

Submit your manuscripts at http://www.hindawi.com
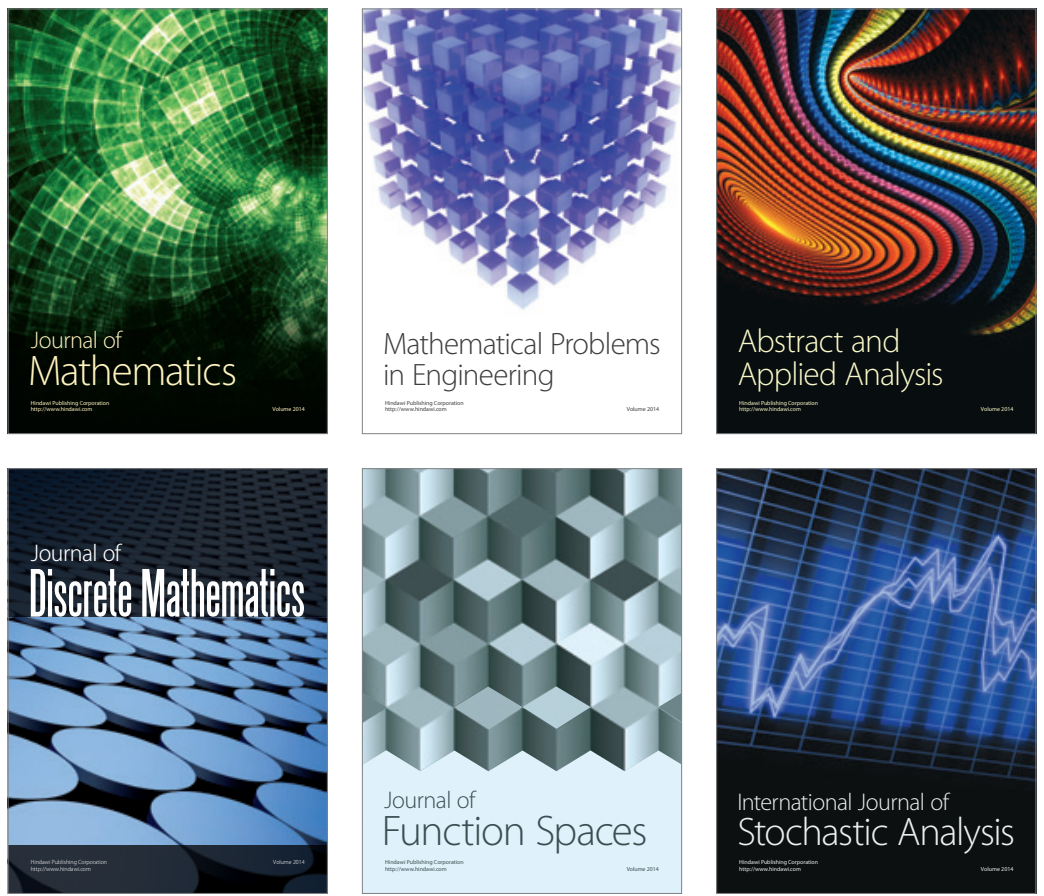

Journal of

Function Spaces

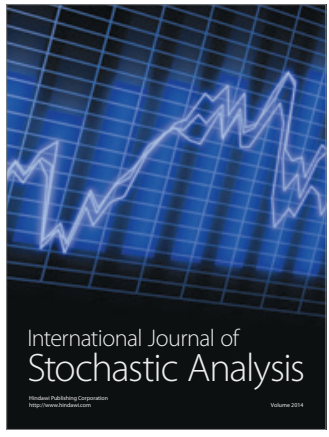

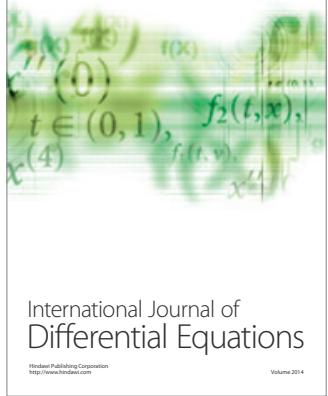
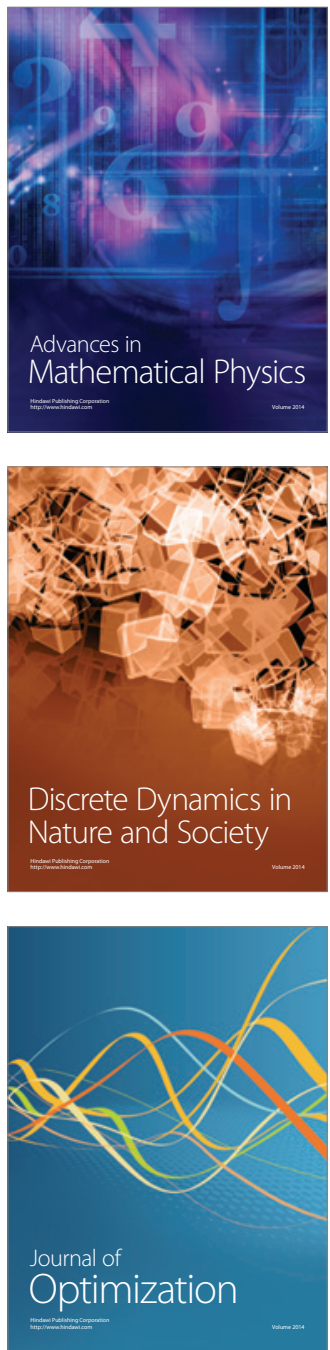